\title{
Medidas preventivas e curativas em saúde bucal nos municípios de Mandaguari e de Sarandi em conjunto com a Pastoral da Criança: um relato de experiência
}

\author{
Preventive and curative measures in oral health in the municipalities of Mandaguari and Sarandi together with
} the Children's Pastoral: an experience report

Medidas preventivas y curativas en salud bucal en los municipios de Mandaguari y de Sarandi en conjunto con la Pastoral del Niño: un relato de experiencia

Bruna Xavier BEZERRA ${ }^{1}$

Maria Eduarda FERNANDES ${ }^{1}$

Flávia Akemi Nakayama HENSCHEL ${ }^{1}$

Laura Moretto MOLINA ${ }^{1}$

Diogo Henrique NAKAIE ${ }^{1}$

Weslley Souza PETYK ${ }^{1}$

Flávia MATARAZZO ${ }^{2}$

Vanessa Cristina VELTRINI ${ }^{2}$

Carlos Alberto Herrero de MORAIS

${ }^{1}$ Graduação em Odontologia, Departamento de Odontologia, UEM Universidade Estadual de Maringá, 87020-900, Maringá - PR, Brasil

${ }^{2}$ Tutoria do Programa PET Odonto, Departamento de Odontologia, UEM Universidade Estadual de Maringá, 87020-900, Maringá - PR, Brasil

\section{Resumo}

O atendimento à Pastoral da Criança tem seu alicerce na atuação do diagnóstico, na prevenção e na utilização de medidas curativas nas crianças de comunidades, bem como permitir a organização do espaço e capacitar líderes voluntários. As pessoas que se voluntariam assumem a tarefa de orientar e de acompanhar as famílias vizinhas em ações básicas de saúde, de educação, de nutrição e de cidadania. O presente trabalho tem como objetivo relatar a experiência nos atendimentos referentes às pastorais das cidades de Sarandi e de Mandaguari, no estado do Paraná, realizados pelo Programa de Educação Tutorial (PET) em Odontologia, com materiais de consumo e instrumentais recebidos por doação e custeios. Foi feita a divisão da equipe em duas: uma para atuar em Mandaguari e outra em Sarandi, nas comunidades Vila Vitória e Boa Vista, Nova Aliança e Jardim São Pedro, das respectivas cidades e suas pastorais. A partir disso, foram ministradas palestras de cunho educativo e preventivo para os adultos uma vez por mês em cada comunidade. No final do ano, foi efetivada uma medida curativa por meio da aplicação do Tratamento Restaurador Atraumático (ART) nas crianças que compareceram no dia e foram avaliadas com a necessidade da utilização da técnica. Com isso, conclui-se que as medidas preventivas e curativas, realizadas pelo grupo PET Odontologia por meio de orientações coletivas e individuais, foram de suma importância para a conscientização sobre a saúde bucal.

Descritores: Prevenção \& Controle; Higiene Bucal; Cárie Dental.

Abstract

The care of the Children's Pastoral has its foundation in acting in the diagnosis, prevention and use of curative measures in the children of the community, as well as to allow the organization of the community and in the training of volunteer leaders. These people who volunteer assume the task of guiding and following the neighboring families in basic actions of health, education, nutrition and citizenship. The objective of this study is to report the experience of Children's Pastoral of Sarandi and Mandaguari, in the state of Paraná, carried out by the Tutorial Education Program. The service is carried out with consumable and instrumental materials received by donation and a large part through costing, and the work is done by dividing the team into two, one to attend in the city of Mandaguari and the other in Sarandi. The families assisted by the Children's Pastoral of the communities Vila Vitória and Boa Vista in Mandaguari-PR, Nova Aliança and Jardim São Pedro in Sarandi - PR, and based on this were given lectures of an educational and preventive nature for adults once a month in each community. At the end of the year, a curative measure was performed through the application of Atraumatic Restorative Treatment (ART) in the children who attended the day and were evaluated with the need to use the technique. With this, it is concluded that the preventive and curative measures carried out by the group PET-Odontologia in the Children's Pastoral are extremely important to raise awareness about oral health through collective and individual guidelines.

Descriptors: Prevention; Oral Hygiene; Dental Caries.

\section{Resumen}

La atención a la Pastoral del Niño tiene su base en la actuacción del diagnóstico, em la prevención y en la utilización de medidas curativas en los niños de las comunidades, así como permitir la organización del espacio y la capacitación de líderes voluntarios. Las personas voluntarias asumen la tarea de orientar y de acompañar a las familias vecinas en acciones básicas de salud, de educación, de nutrición y de ciudadanía. Este trabajo tiene como objetivo relatar la experiencia en las atenciones referentes a las pastorales de Sarandi y de Mandaguari, en el estado de Paraná, realizados por el Programa de Educación Tutorial (PET) em Odontología, con materiales de consumo e instrumentales recibidos por donación y costeos. Se hizo la división del equipo en dos: una para actuar en Mandaguari y otra en Sarandi, em las comunidades Vila Vitória y Boa Vista, Nova Aliança y Jardim São Pedro, de las respectivas ciudades e sus pastorales. A partir de eso, fueran ministradas conferencias de cuño educativo y preventivo para los adultos una vez cada mes en cada comunidad. A final del año se realizó una medida curativa por medio de la aplicación del Tratamiento Restaurador Atraumático (ART) en los niños que asistieron el día y fueron evaluados con la necesidad de la utilización de la técnica. Con ello, se concluye que las medidas preventivas y curativas realizadas por el grupo PET Odontología, por medio de orientaciones colectivas y individuales, fueran de suma importancia para concientizar sobre la salud bucal.

Descriptores: Prevención \& Control; Higiene Bucal; Caries Dental.

\section{INTRODUÇÃO}

O projeto intitulado "Inserção de ações em saúde bucal junto à Pastoral da Criança nos municípios de Mandaguari e Sarandi - PR" foi criado em 2000 pelo Programa de Educação Tutorial (PET) do curso de Odontologia da Universidade Estadual de Maringá (UEM). O PET é um grupo desenvolvido por estudantes com a tutoria de um docente, organizados a partir de formações em nível de graduação nas instituições de ensino superior do País e orientados pelo princípio da indissociabilidade entre ensino, pesquisa e extensão a partir da educação tutorial. Há projetos específicos para cada uma das diretrizes, mas o intuito é abranger os três pilares em apenas um projeto ${ }^{1}$.

Realizar visitas anuais a cada uma das quatro comunidades atendidas pela Pastoral da Criança Vila Vitória e Boa Vista em Mandaguari - PR, e Nova Aliança e Jardim São Pedro em Sarandi - PR - 
é o intuito do projeto, que visa a promoção da saúde por meio de ações que envolvem a aplicação da tríade ensino, pesquisa e extensão como instrumento de intervenção ${ }^{1}$. Pelo fato de as comunidades estarem situadas nesses municípios, o projeto atende a crianças entre 0 e 6 anos de idade e suas famílias.

De acordo com o Ministério da Saúde, a cárie dentária é o maior problema de saúde bucal no Brasil e acarreta consequências físicas, sociais e psicológicas, sendo considerada manifestação clínica de uma infecção bacteriana ${ }^{2,3}$. Possui caráter multifatorial $^{4}$, que, se não tratada, resulta na destruição dos tecidos dentais. Está relacionada a elementos como: hábitos alimentares, higienização oral, qualidade salivar, carga genética ${ }^{3,5} \mathrm{e}$, em alguns casos, condições socioeconômicas ${ }^{4}$. Informações acerca dos problemas bucais, como tratá-los e preveni-los devem ser transmitidas constantemente, de preferência por profissionais devidamente instruídos. É essencial que os pais ou os responsáveis estejam cientes sobre a importância do cuidado com a saúde bucal dos seus filhos, especialmente no que diz respeito à cárie, devido à alta prevalência no país. Toda as providências devem ser tomadas para evitar esse problema.

A Odontologia Preventiva ${ }^{6,7}$ tem papel fundamental nesse cenário, uma vez que contribui para a promoção da saúde e para a ampliação do conhecimento necessário sobre os prejuízos que a ausência da saúde bucal pode desenvolver ${ }^{4}$. Por meio dela, é possível conferir ao paciente autonomia e responsabilidade sobre a própria higienização. Como o crescimento e o desenvolvimento da criança são fortemente influenciados pelo ambiente de convívio e pelos hábitos familiares, a Pastoral da Criança parece ser um contexto favorável para a adoção de medidas educativas, preventivas e curativas.

Dentro do projeto, a Odontologia Curativa aparece nos momentos em que é realizado o Atraumatic Restorative Treatment (ART) ${ }^{8}$, também conhecido como Tratamento Restaurador Atraumático, método alternativo, definitivo e pouco invasivo, que tem como objetivo conter o avanço das lesões cariosas em populações carentes, nas quais é alta a prevalência da doença cárie, proporcionando melhoria na qualidade de vida desses pacientes ${ }^{3,8}$. O procedimento prevê a manutenção de uma estreita camada de tecido afetada por cárie, sob o Cimento de Ionômero de Vidro (CIV), material de eleição, que libera flúor, adere às estruturas dentárias e dispensa retenções adicionais, além de ser um excelente material por sua biocompatibilidade ${ }^{8,9}$.

O método consiste na intervenção mínima e na realização de restaurações com utilização de instrumentos manuais sem a necessidade de anestesia ou de isolamento absoluto ${ }^{8,9}$. Pode ser utilizado tanto em consultórios quanto em locais não tão equipados - como acontece nas atividades da Pastoral da
Criança, uma vez que pouca infraestrutura é requerida. A indicação do ART requer presença de cárie, ausência de dor espontânea, cavidade sem comprometimento pulpar e acesso compatível ao tamanho de instrumentos manuais ${ }^{8,9}$. Caso sejam observadas condições em que a criança já tenha cárie com exposição pulpar, dor, necessidade de uso de instrumentos rotatórios, isto é, seja preciso anestesiar pela severidade da lesão, os pais ou os responsáveis são orientados para que procurem atendimento odontológico na rede pública o mais rápido possível, alertando-os sobre a importância dos cuidados necessários.

\section{MATERIAL E MÉTODO}

O trabalho com o projeto do PET foi realizado em 2017 mediante divisão da equipe: uma para comparecer no município de Mandaguari e outra em Sarandi. As amostras utilizadas foram as famílias atendidas pela Pastoral da Criança das comunidades Vila Vitória e Boa Vista, de Mandaguari, e Nova Aliança e Jardim São Pedro, de Sarandi. Foram ministradas palestras de cunho educativo e preventivo para os pais uma vez por mês em cada comunidade. Nos atendimentos odontológicos, que ocorreram mensalmente, além do exame clínico da cavidade bucal quanto à presença de cárie, também eram efetuadas orientações personalizadas de como os pais ou os responsáveis deveriam realizar a higiene bucal dos filhos, instruções sobre a dieta e o encaminhamento para a UBS mais próxima do município ou, quando possível, para a Clínica Odontológica da Universidade Estadual de Maringá (UEM), de acordo com a necessidade da criança.

Durante $o$ atendimento, foi feito o levantamento epidemiológico, no qual um formulário específico era preenchido com os dados da criança e do responsável, as características bucais da criança atendida e sua classificação de acordo com sua necessidade de atendimento, que poderia ser: verde ausência de necessidade; azul - sem urgência; ou vermelho - com urgência. Ainda no formulário, era descrito o procedimento realizado nos casos necessários e os responsáveis deveriam assinar como forma de consentimento. Os dados analisados e comparados a cada atendimento foram utilizados para a elaboração de artigos e de trabalhos apresentados em eventos da área. Para a realização das tarefas descritas, os participantes foram divididos em pequenos grupos com, pelo menos, um membro de cada série da graduação. Cada discente exercia sua função de acordo com a série correspondente: os da terceira série realizavam anotações dos dados no formulário, os da quarta examinavam a cavidade bucal das crianças e os da quinta realizavam a técnica restauradora atraumática nos pacientes em que havia necessidade. No mérito da informação e da orientação personalizada, todos os membros contribuíram com seus conhecimentos. 


\section{RESULTADOS E DISCUSSÃO}

Foram avaliadas, no total, 136 crianças durante os seis encontros de levantamento epidemiológico e de execução da técnica ART realizados em cada uma das quatro comunidades -78 em Mandaguari e $58 \mathrm{em}$ Sarandi. Após o levantamento epidemiológico da doença cárie, cada criança foi classificada por cor. Em Mandaguari, 51 crianças foram classificadas como verde, 24 como azul e 3 como vermelho. Em Sarandi, 36 foram classificadas como verde, 19 como azul e 3 como vermelho.

A quantidade de crianças avaliadas supriu as expectativas do grupo, assim como o levantamento epidemiológico e a qualidade dos tratamentos restauradores atraumáticos efetuados, uma vez que o grupo precisou adaptar-se à estrutura dos locais. Foram utilizados os salões paroquiais comunitários, que contavam com algumas mesas, cadeiras e bancos de madeira. Além dos instrumentais e materiais curativos utilizados para o tratamento, eram levados alguns colchonetes durante as visitas, acomodados sobre as mesas ou os bancos previamente higienizados, para que as crianças atendidas tivessem maior conforto. Quando a visita tinha como objetivo ministrar uma palestra, eram levados extensão, notebook e projetor.

Com relação às limitações e às dificuldades encontradas, percebeu-se um decréscimo na adesão às palestras quando estas não estavam associadas a algum outro tipo de serviço, como escovação supervisionada, por exemplo. Com isso, o grupo definiu que as palestras estariam sempre em conjunto com alguma atividade.

Durante todo o ano, o grupo pôde perceber a abertura e a receptividade dos líderes pastorais, das famílias e das crianças da comunidade. Tanto as informações e as recomendações quanto o tratamento oferecido pelos discentes foram naturalmente acolhidos e valorizados. Devido à frequência mensal das visitas, o vínculo com a comunidade foi aprimorado gradativamente ao longo do tempo.

A experiência trouxe resultados para a comunidade assistida, que gerou impacto em cerca de 320 famílias orientadas e informadas no que diz respeito à saúde bucal, e também no grupo, pois permitiu aos acadêmicos e aos tutores integrantes crescimentos em níveis profissional e pessoal por meio do contato com a população para além dos muros da academia. Ademais, possibilitou a coleta de dados, que serão utilizados para a produção de um projeto de pesquisa, contribuindo, assim, com a comunidade científica.

\section{CONCLUSÃO}

Foi possível perceber que líderes, crianças, pais, mães e responsáveis foram conscientizados sobre a importância da saúde bucal por meio das orientações coletivas e individuais oferecidas. A saúde bucal das crianças atendidas melhorou, não só porque houve ações preventivas aliadas a intervenções curativas, mas também pelo acompanhamento em longo prazo e pelas palestras de conscientização sobre saúde bucal.

\section{AGRADECIMENTOS}

Ao Programa de Educação Tutorial (PET) do MEC em conjunto com a Pró-Reitoria de Ensino (PEN) da Universidade Estadual de Maringá (UEM) pelo fomento da bolsa.

À Universidade Estadual de Maringá pelo fomento da bolsa ao projeto de extensão "Inserção de ações em saúde bucal junto à Pastoral da Criança nos municípios de Mandaguari e Sarandi - PR".

À Pastoral da Criança Nossa Senhora Aparecida, de Mandaguari - PR, e à Pastoral da Criança da Paróquia Nossa Senhora das Graças, de Sarandi - PR, por terem fornecido espaço e tempo para a realização do projeto. Agradecimento especial às líderes, que sempre foram o intermédio entre os acadêmicos, agendando os encontros de forma muito prestativa.

À Colgate - Palmolive Comercial Ltda - São Paulo - SP, por apoiar o projeto com a doação de materiais de consumo.

\section{REFERÊNCIAS}

1. Ministério da Educação. Apresentação - PET. 2018. Disponível em: http://portal.mec.gov.br/pet. Acesso em 15 jul. 2019.

2. Ministério da Saúde. Saúde Bucal. 1. ed. Brasília: Ministério da Saúde; 2008.

3. Braga MLA, Pereira EL, Palmeira JT, Costa LED, Maia $\mathrm{MCB}$, Oliveira OL et al.Fatores associados à cárie dentária na primeira infância. Arch Health Invest. 2018;7 (Spec Iss 7):59.

4. Costa SM, Delário AK, Vasconcelos M, Abreu MHNG. Modelos explicativos da cárie dentária: do organicista ao ecossistêmico. Pesq Bras Odontoped Clin Integr. 2012;12(2):285-91.

5. Souza EJ, Oliveira Neto JB, Silva IL, Sousa SCA, Araújo OSM, Oliveira Filho AA. O papel da sacarose na formação da cárie dental: uma breve revisão. Arch Health Invest. 2018;7(Spec Iss 7):75.

6. Bento AKM, Sousa JB, Queiroz LGS, Silva CHF. Odontologia social e preventiva: um estudo epidemiológico de moradores de uma comunidade. EEDIC. 2017;4(1).

7. Sousa JB, Bento AKM, Queiroz LGS, Silva CHF. Odontologia e comunidade: relato de experiência de alunos do programa de iniciação científica da Unicatólica. EEDIC. 2017;4(1).

8. Lima DC, Saliba NA, Moimaz SAS. Tratamento restaurador atraumático e sua utilização em saúde pública. RGO, 2008;56(1):75-9.

9. Santos LN, Guedes SAG. Tratamento restaurador atraumático em saúde coletiva [monografia]. Aracaju: Universidade Tiradentes; 2013. 


\section{CONFLITO DE INTERESSES}

Os autores declaram não haver conflitos de interesse.

\section{AUTOR PARA CORRESPONDÊNCIA}

\section{Weslley Souza Petyk}

Departamento de Odontologia

Universidade Estadual de Maringá - UEM

Av. Mandacaru, 1550,

Bloco S08, Maringá, PR, Brasil 87083-170

weslleypetyk@gmail.com

Submetido em 25/07/2019

Aceito em 20/04/2020 